\title{
INFLUENCE OF ULTRASONIC ASSISTANCE ON DELAMINATION DURING MACHINING OF DifFERENT COMPOSITE MATERIALS
}

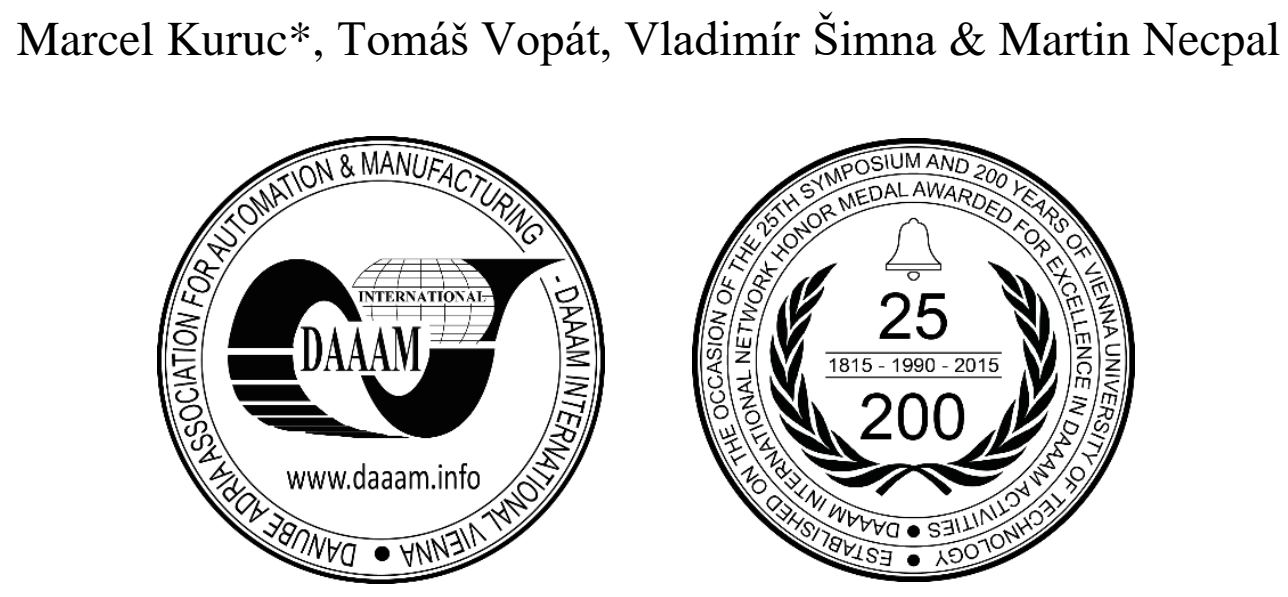

This Publication has to be referred as: Kuruc, M[arcel]; Vopat, T[omas]; Simna, V[ladimir] \& Necpal, M[artin] (2017). Influence of Ultrasonic Assistance on Delamination During Machining of Different Composite Materials, Proceedings of the 28th DAAAM International Symposium, pp.0392-0399, B. Katalinic (Ed.), Published by DAAAM International, ISBN 978-3-902734-11-2, ISSN 1726-9679, Vienna, Austria

DOI: $10.2507 / 28$ th.daaam.proceedings.055

\begin{abstract}
A lot of nowadays researches are focused on increasing strength of the components and decreasing their weight, or obtaining unique properties. Composite materials are one of the results of the researches. However, different material properties of matrix and reinforcing material usually cause certain difficulties during conventional machining, such as rapid tool wear and delamination of composite. Therefore, focusing on machinability of this kind of materials is necessary. Scientists have discovered several ways of how to satisfactorily machine different composite materials. Seco Tools Company starts developing a new design of the cutting tools. Researchers of the Stanford University have devised a diamond-like carbon (DLC) coating available to effectively cut matrix as well as reinforce fibres. DMG Mori Company has implemented ultrasonic assistance into machining process and reached enhanced machinability. This article compares conventional milling and ultrasonic assisted milling of the composite materials - glass fibre reinforced plastic (GFRP) and two types of carbon fibre reinforced plastics (CFRP) by using a special designed cutting tool. The results could be applied to determine when ultrasonic assistance is advantageous and what advantages it brings about. The purpose of this study is to determine ways to increase efficiency and productivity of machining different types of composite materials.
\end{abstract}

Keywords: Ultrasonic assisted milling; Composite materials; GFRP; CFRP; Delamination; Advanced machining.

\section{Introduction}

Composite materials are widely used in many applications in many fields, such as aerospace, aviation (Fig. 1.), marine, automotive, industry, medicine, sport and many others. Different mechanical properties of each compound in composite material cause challenges in its machining. Recommended machining parameters for hard and strong materials such as reinforcing fibre are different from the machining parameters for soft and tough materials such as matrix. That means, the machining parameters proper for one compound may be improper for other compounds. Improper machining parameters could cause melting of the matrix, tearing out the fibres, edge-chipping of the composite, rapid tool wear, formation of build-up-edges (BUE), etc. [1,2] 


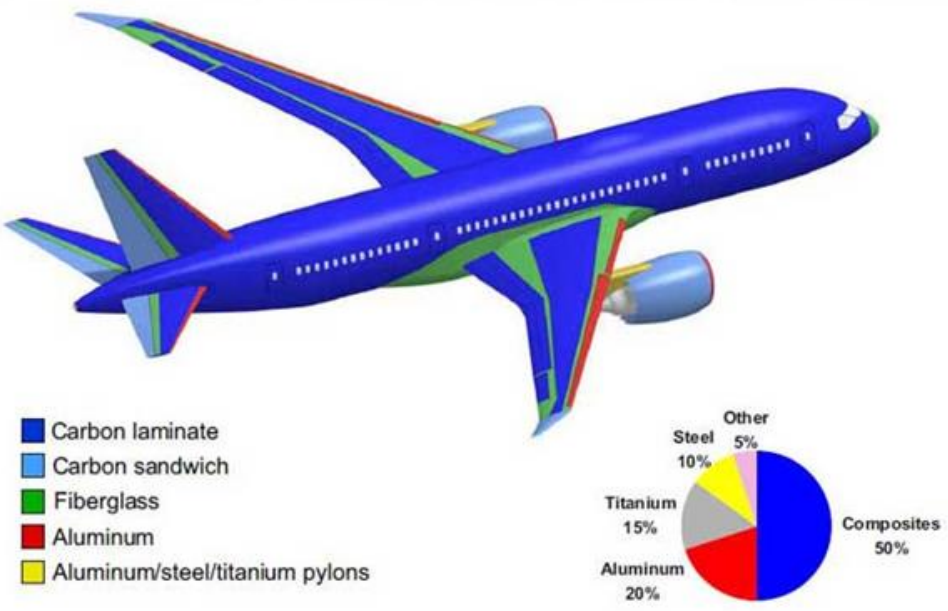

Fig. 1. Composite materials in Boeing 787 [2]

Different attitudes have been suggested to solve the problems, one of them being enchanting of the cutting tool geometry and design. Newly developed cutting tools for machining composite materials are typical by unusual shape. They could have additional notches on the teeth, and/or arrow shaped double screw, or pineapple-like shape, as is shown in Fig. 2. Another attitude is focused on advanced coatings, such as diamond or DLC (diamond like carbon) coated cutting tools. Another way to improve machining of composite materials is ultrasonic assistance. Ultrasound avoids creation of BUE, reduces cutting force and process heat. Resultant cutting parameters are still affected by the type of matrix and the type of reinforcing material. Also, different cutting parameters will be set for roughing and finishing $[3,4,5,6,7,8,9$, $10]$.
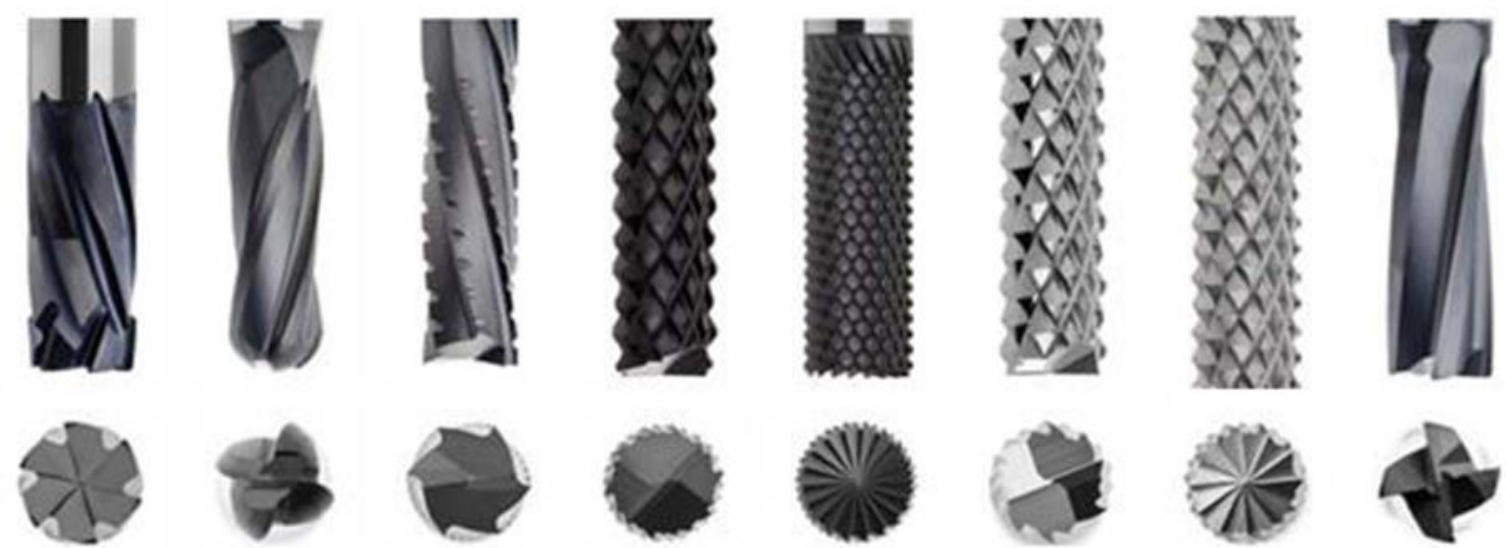

Fig. 2. Advanced design of milling cutters [11]

\section{Machining method}

A machine tool for rotary ultrasonic machining (RUM) was applied in this experiment. RUM usually utilize ultrasonic tool with diamond particles and undefined geometry. This tool rotates around the vertical axis and oscillates by ultrasonic frequency in vertical direction. Accordingly, very hard and brittle materials (such as ceramics) can be machined. When a tool with defined geometry (e.g. conventional milling cutter) is applied, the process is called ultrasonic assisted machining (UAM). RUM and UAM have a lot of common advantages, such as decrease of cutting force, reduction of heat generation, elimination of BUE formation, superior machined surface, increased tool life, etc. Generally, RUM is proper for the hard and brittle materials (such as optic glass), while UAM is proper for the soft and tough materials (such as metals and polymers). RUM and UAM execute similar movements, and therefore they could be usually performed on the same machine tool.

In this experiment, rotary ultrasonic milling machine DMG ULTRASONIC 20 linear (Fig. 3.) was used. This machine tool can operate continuously in five axes and it can operate as a conventional milling machine, high speed cutting machine, high feed milling machine, ultrasonic assisted milling machine and rotary ultrasonic milling machine. It is therefore able to machine almost every material $[12,13,14]$. 


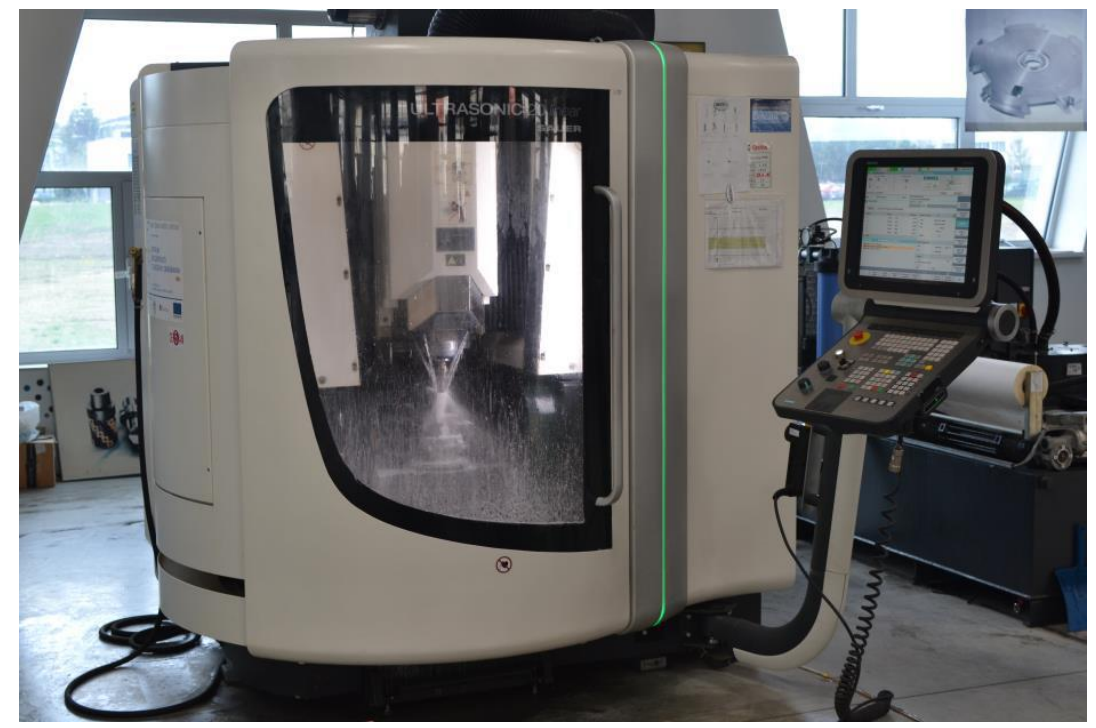

Fig. 3. Rotary ultrasonic machine tool DMG Ultrasonic 20 linear

As a cutting tool, a milling cutter for composite materials Fiber Line Honeycomb Hexacut - Fräse (Hexacut - End mill) with internal labelling 068HOA050 manufactured by Hufschmied Zerpanungssysteme was used. This tool has the cutting diameter of $5 \mathrm{~mm}$, cutting length of $18 \mathrm{~mm}$, shank diameter of $6 \mathrm{~mm}$, overall length of $60 \mathrm{~mm}$ and $8 \mathrm{flutes}$ (Fig. 4.). A $3 D$ model of the workpiece was created by CAD software Autodesk PowerShape Ultimate 2017 and the NC program for machining (for control system Siemens Sinumerik 840D Solutionline) was generated by CAM software Autodesk PowerMill Ultimate 2017 [15, 16, 17, 18].

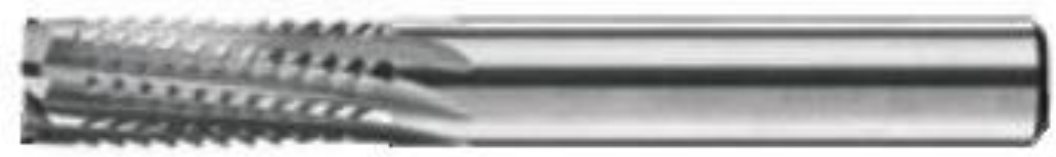

Fig. 4. Milling cutter Hexacut for composite materials

\section{Description of the experiment}

As workpiece materials, a glass fibre reinforced polymer (GFRP) and two types (M \& S) of carbon fibre reinforced polymers (CFRP) were used. These composite materials have different mechanical properties, as shown Fig. 5.

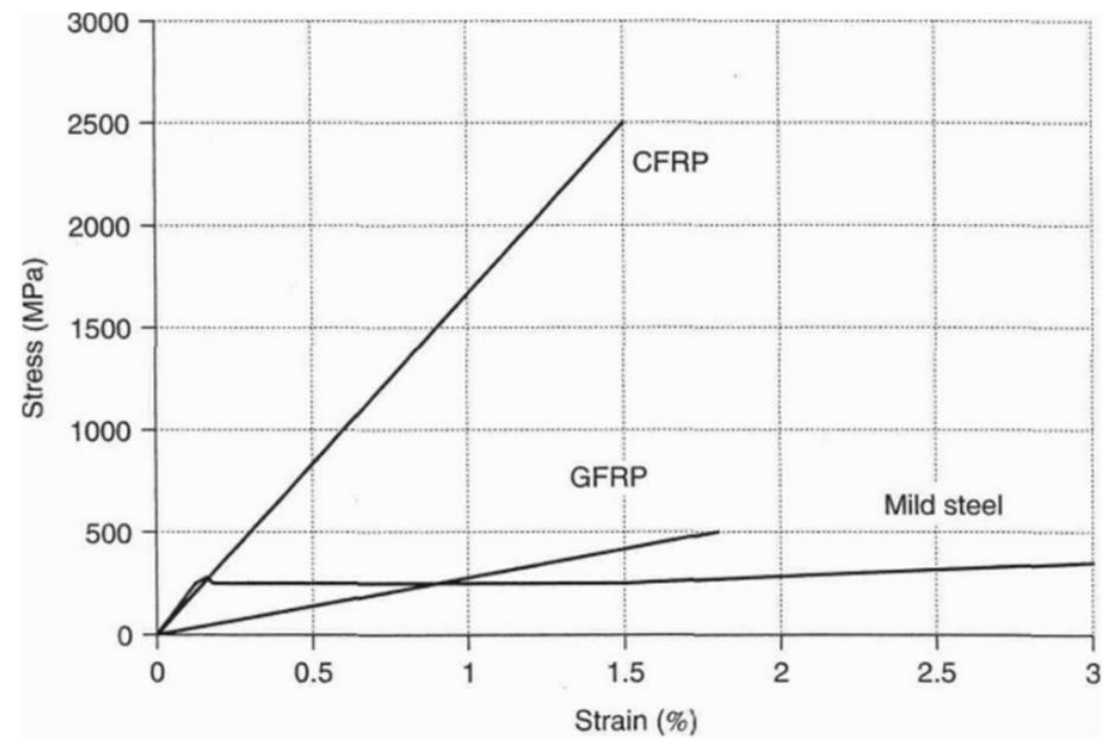

Fig. 5. Comparison of Yield stress for different materials [2] 
GFRP material was provided by the Slovak company Armastek. Producer determine following mechanical properties: modulus of elasticity $21 \mathrm{GPa}$, tensile strength $190 \mathrm{MPa}$, yield strength $140 \mathrm{MPa}$, density $1850 \mathrm{~kg} . \mathrm{m}^{-3}$. The specimen was of a rod shape with rectangular section with filled edges with the dimensions $40 \times 30 \mathrm{~mm}$. Fibre orientation was parallel with the axis of the rod. The following cutting conditions were set up for every experiment, according to the SECO catalogue: cutting speed $50 \mathrm{~m} / \mathrm{min}$ (spindle speed $3183 \mathrm{rpm}$ ), feed per tooth $0.015 \mathrm{~mm}$ (feed rate $382 \mathrm{~mm} / \mathrm{min}$ ) and depth of cut $0.7 \mathrm{~mm}$. During ultrasonic machining, it is recommended to use harmonic frequency of the tool which was 23,500 $\mathrm{Hz}$.

CFRP materials were provided by the Czech company Sanax (type S \& M). Producer determine following mechanical properties: modulus of elasticity $170 \mathrm{GPa}$, tensile strength $3000 \mathrm{MPa}$, elongation $1.3 \%$, density $1550 \mathrm{~kg} . \mathrm{m}^{-3}$ for type S and modulus of elasticity $210 \mathrm{GPa}$, tensile strength $2480 \mathrm{MPa}$, elongation $1.1 \%$, density $1550 \mathrm{~kg} . \mathrm{m}^{-3}$ for type $\mathrm{M}$. The specimens were a plate shape with the dimensions of $50 \times 180 \times 1.4 \mathrm{~mm}$. The following cutting conditions were set up, according to the also SECO catalogue: cutting speed $100 \mathrm{~m} / \mathrm{min}$ (spindle speed $6366 \mathrm{rpm}$ ), feed per tooth $0.015 \mathrm{~mm}$ (feed rate $764 \mathrm{~mm} / \mathrm{min}$ ) and depth of cut $0.7 \mathrm{~mm}$. During ultrasonic machining, it is recommended to use harmonic frequency of the tool which was $23,500 \mathrm{~Hz}$ (the same cutting tool was used in all experiments) [19].

Eight notches were manufactured into GFRP. Two notches are parallel with the fibres, two notches were perpendicular to fibres. They were placed on the lateral surface of the rod. On the base surface four notches to the previous ones were placed. Half of the notches were machined without ultrasonic assistance and the rest of them with assistance of ultrasound. The notches were $1.4 \mathrm{~mm}$ deep. After machining, the specimen was digitised by GOM ATOS II TripleScan. Its precision is $0.02 \mathrm{~mm}$. This device, as well as specimen prepared for 3D scanning are shown in Fig. 6.
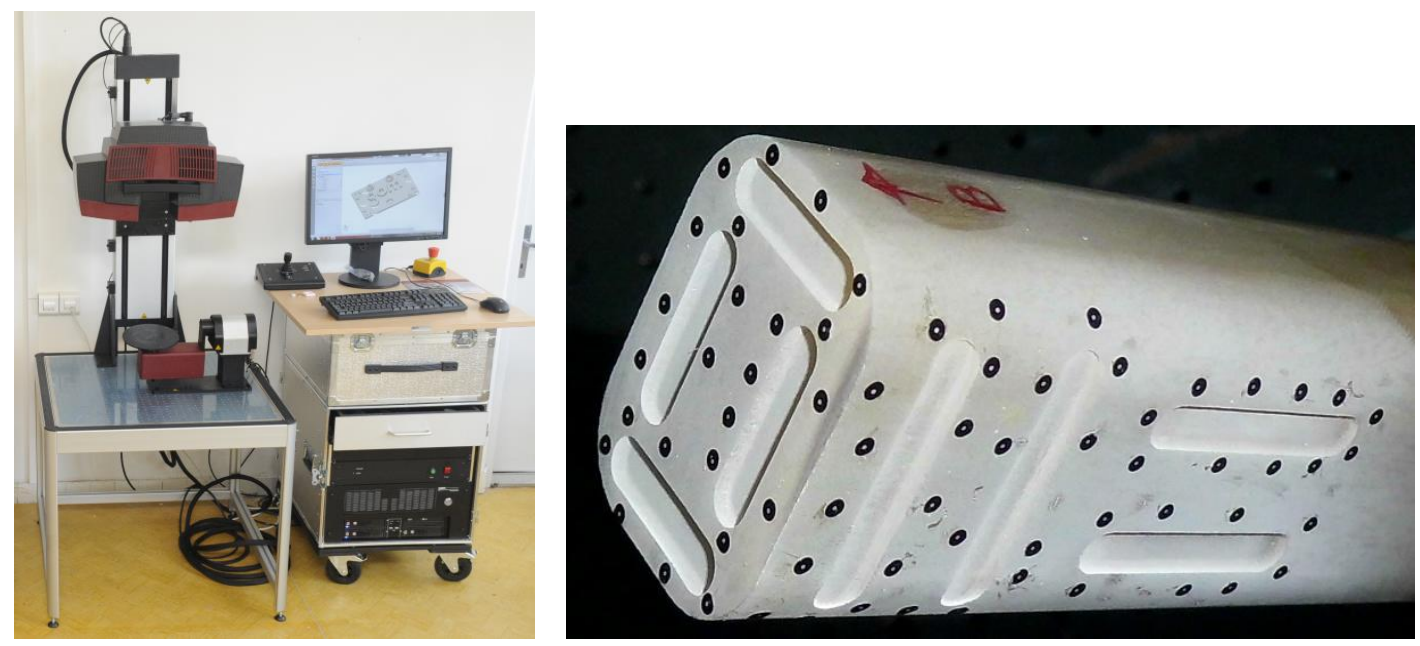

Fig. 6. Scanning device and prepared specimen

Eight notches were performed into each CFRP as well. Two notches were parallel with the fibres, two notches were perpendicular to the fibres. They were placed on the biggest surface of the rod. On the edges of CFRP, four notches to the previous ones were placed. Half of the notches were machined without ultrasonic assistance and the rest of them with the assistance of ultrasound. The notches were $0.7 \mathrm{~mm}$ deep. After machining, the specimens were digitized by Zeiss Metrotom 1500 computer tomography. The device, as well as its result of digitization are shown in Fig 7.
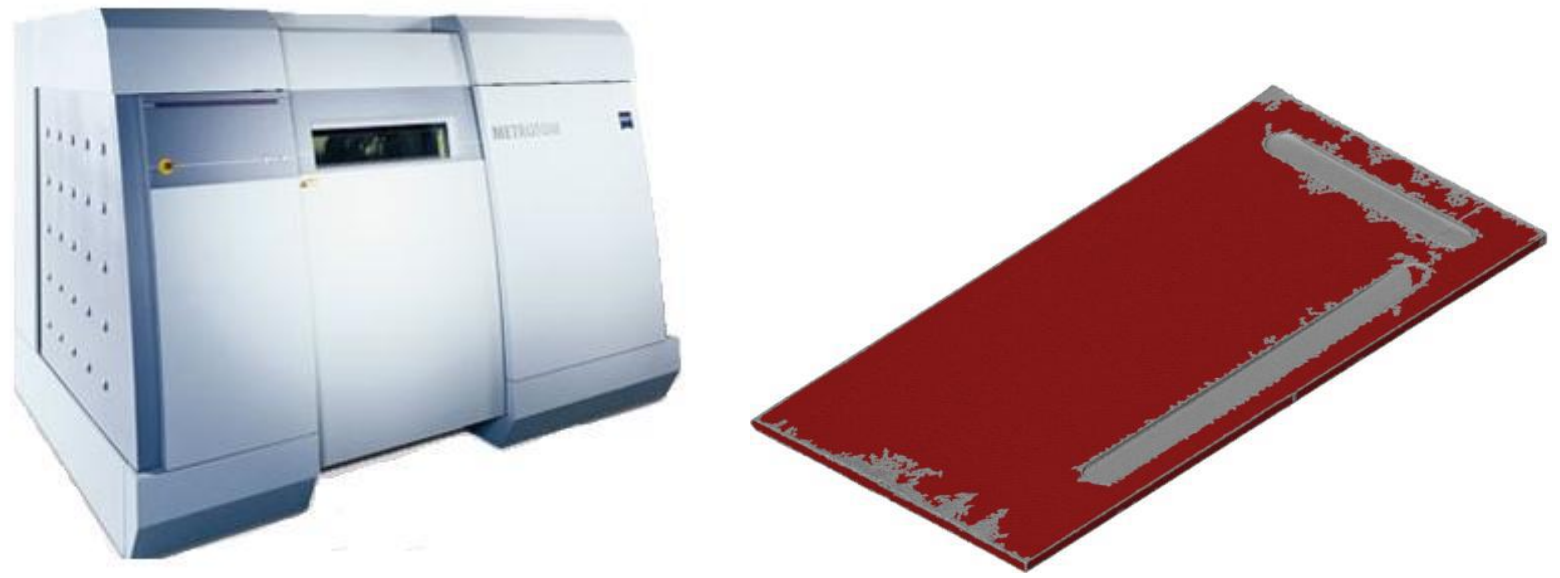

Fig. 7. Scanning device and digitised specimen [20] 
Digitised models were compared with the original CAD model. Delamination was evaluated as the highest width of each notch (original width was $5 \mathrm{~mm}$ ). Beside delamination, the machine load (in Z direction) and surface roughness were also evaluated (they are often connected with delamination itself). Machine load was obtained directly by the machine tool. Surface roughness was measured by ZEISS Surfcom 5000, which is shown in Fig. 8.

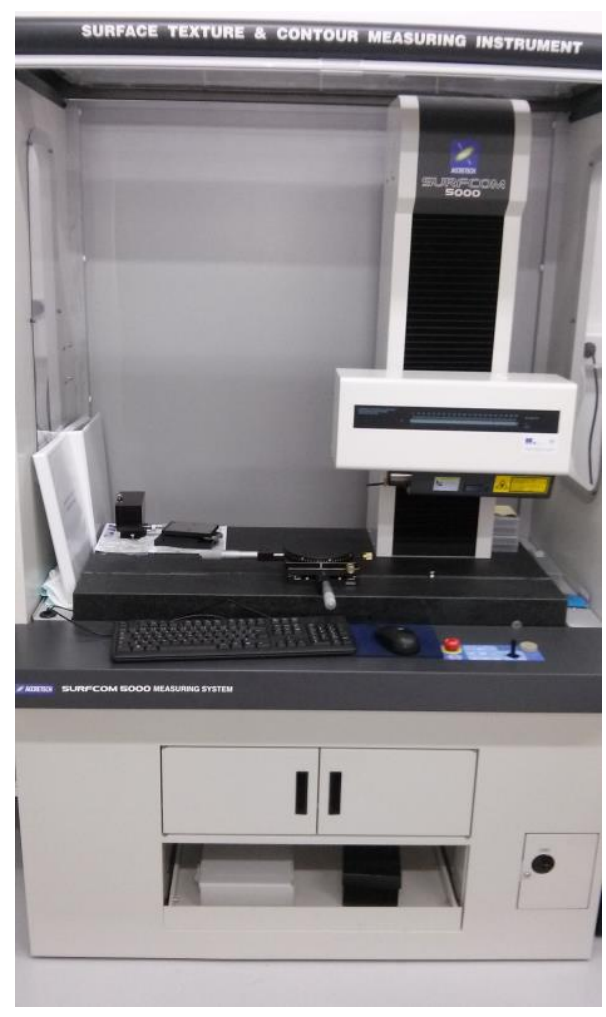

Fig. 8. Surface roughness measuring device [21]

\section{Results of the experiment}

Several factors of the delamination were obtained and evaluated, such as delamination width, machine tool load and surface roughness of composite materials. They were achieved for each machined notch. Labelling of the notches in GFRP is shown in Fig. 9. The green ones (letter "a") were machined without ultrasound. The blue ones (letter "b") were machined with ultrasonic assistance. Direction of the fibres is parallel with the groove numbered 2.
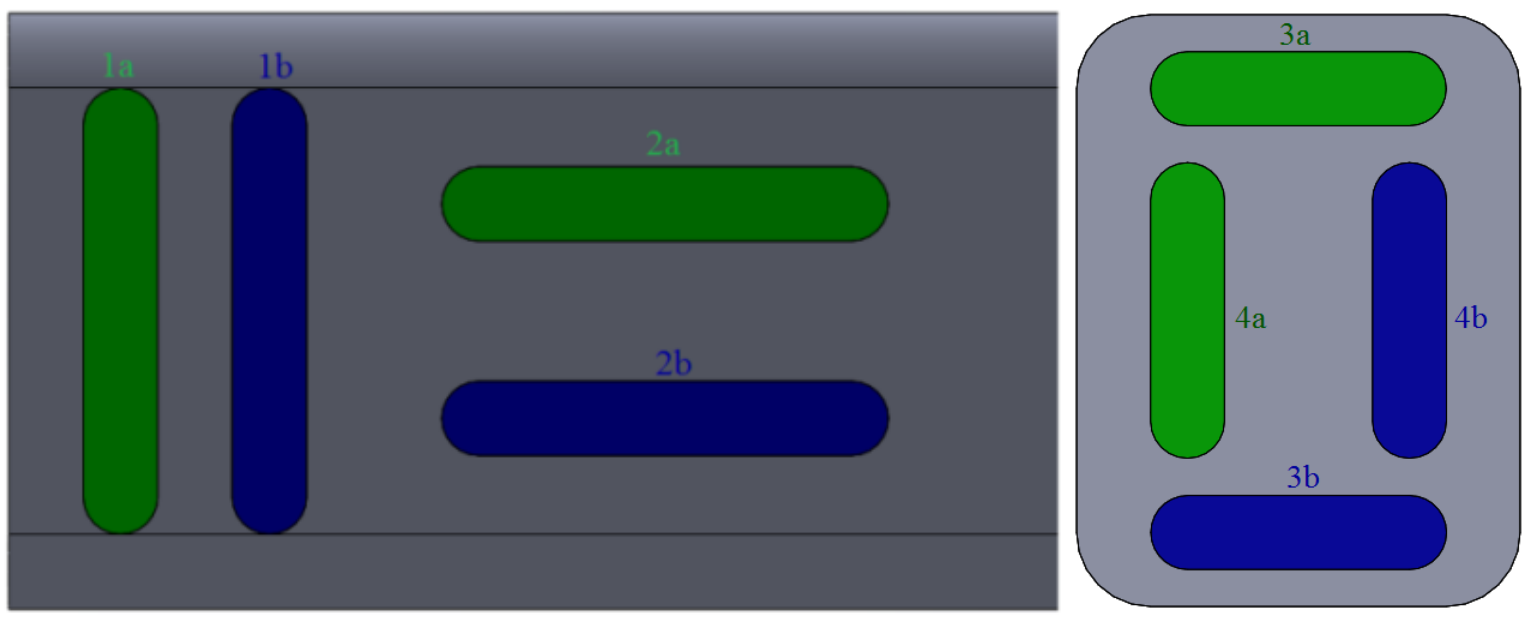

Fig. 9. Labeling of the notches

Labelling of the notches in CFRP is shown in Fig. 10. An extra notch (continuous one) was produced for easier determination of position. The green ones (letter "a") were machined without ultrasound. The blue ones (letter "b") were machined with ultrasonic assistance. Direction of the fibres is parallel with the grooves numbered 1 and 4. 

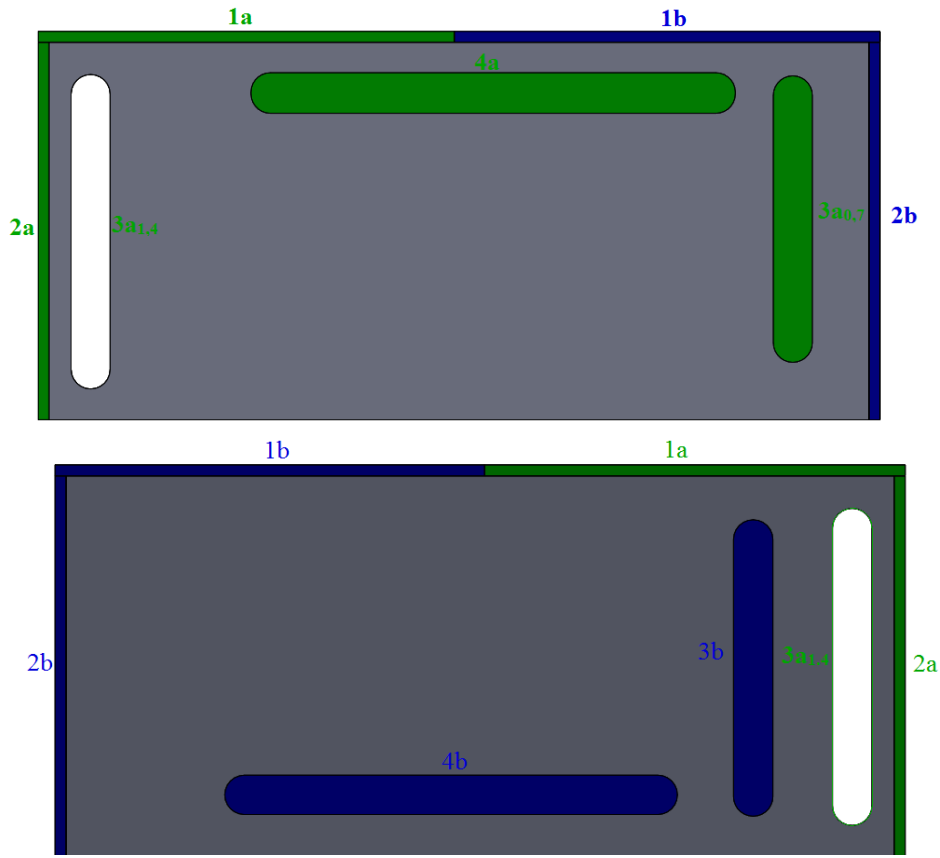

Fig. 10. Labelling of the notches (top and bottom side)

Results of the measurements are summarized in Tables 1, 2 and 3. Recorded are only average values (each measurement was repeated three times). In the Table, machine tool load (represent cutting force) in $\mathrm{Z}$ direction is labelled as Load Z, and it is the percentage of the maximum available load of the machine tool, measured directly by the machine tool. Delamination factor is labelled as $D f$ and it is the percentage difference between the recommended width of the notch and the real width of the notch. It is expressed in Fig. 11. and by formula (1). As roughness parameters, its average $(R a)$ and maximum $(R z)$ values were chosen.

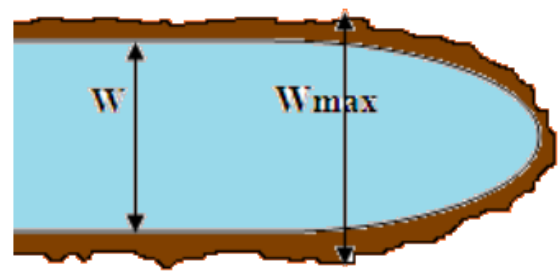

Fig. 11. Delamination of the notch

Turquoise colour represents recommended width of the notch (W) and brown colour represent the real (maximum) width of the notch $\left(\mathrm{W}_{\max }\right)$. According Fig. 11. is possible to calculate delamination factor by following formula:

$D_{f}=\left(\frac{W_{\max }-W}{W}\right) \times 100 \quad[\%]$

\begin{tabular}{|c|c|c|c|c|}
\hline GFRP & $\begin{array}{c}\text { Load Z } \\
{[\mathbf{\%}]}\end{array}$ & $\begin{array}{c}\text { Df } \\
{[\mathbf{\%}]}\end{array}$ & $\begin{array}{c}\mathbf{R a} \\
{[\boldsymbol{\mu \mathbf { m } ]}}\end{array}$ & $\begin{array}{c}\mathbf{R z} \\
{[\boldsymbol{\mu m}]}\end{array}$ \\
\hline 1a & 10 & 11.2 & 2.81 & 17.98 \\
\hline b & 5 & 14.8 & 2.86 & 17.25 \\
\hline $2 \mathrm{a}$ & 10 & 4.6 & 3.16 & 18.25 \\
\hline $2 \mathrm{~b}$ & 5 & 3.6 & 3.18 & 17.35 \\
\hline $3 \mathrm{a}$ & 10 & $<0.2$ & 1.49 & 9.27 \\
\hline $3 \mathrm{~b}$ & 5 & $<0.2$ & 1.56 & 10.59 \\
\hline $4 \mathrm{a}$ & 15 & $<0.2$ & 1.58 & 11.42 \\
\hline $4 \mathrm{~b}$ & 10 & $<0.2$ & 1.59 & 11.42 \\
\hline avg. a & $\mathbf{1 1 . 2 5}$ & $\mathbf{7 . 9}$ & $\mathbf{2 . 2 6}$ & $\mathbf{1 4 . 2 3}$ \\
\hline avg. b & $\mathbf{6 . 2 5}$ & $\mathbf{9 . 2}$ & $\mathbf{2 . 2 9}$ & $\mathbf{1 4 . 1 5}$ \\
\hline
\end{tabular}

Table 1. Results of the measurements for GFRP 
Value of width of the delamination less than $0.2 \%$ means, that there is present delamination lesser than accuracy of the digitization device. Therefore, it cannot be calculated (it looks like there is no delamination).

\begin{tabular}{|c|c|c|c|c|}
\hline CFRP-S & $\begin{array}{c}\text { Load } Z \\
{[\mathbf{\%}]}\end{array}$ & $\begin{array}{c}\text { Df } \\
{[\mathbf{\%}]}\end{array}$ & $\begin{array}{c}\mathbf{R a} \\
{[\boldsymbol{\mu \mathbf { m } ]}}\end{array}$ & $\begin{array}{c}\mathbf{R z} \\
{[\boldsymbol{\mu m}]}\end{array}$ \\
\hline 1a & 15 & 3.8 & 1.25 & 7.43 \\
\hline bb & 5 & 1.9 & 1.15 & 7.34 \\
\hline $2 \mathrm{a}$ & 10 & 29.4 & 1.09 & 7.83 \\
\hline $2 \mathrm{~b}$ & 5 & 38.1 & 0.92 & 6.92 \\
\hline $3 \mathrm{a}$ & 15 & 24.6 & 1.96 & 17.08 \\
\hline $3 \mathrm{~b}$ & 5 & 17 & 2.15 & 18.60 \\
\hline $4 \mathrm{a}$ & 10 & 21.8 & 1.46 & 8.71 \\
\hline 4b & 5 & 14.2 & 1.45 & 9.42 \\
\hline avg. a & $\mathbf{1 2 . 5}$ & $\mathbf{1 9 . 9}$ & $\mathbf{1 . 4 4}$ & $\mathbf{1 0 . 2 6}$ \\
\hline avg. b & $\mathbf{5}$ & $\mathbf{1 7 . 8}$ & $\mathbf{1 . 4 2}$ & $\mathbf{1 0 . 5 7}$ \\
\hline
\end{tabular}

Table 2. Results of the measurements for CFRP type S

\begin{tabular}{|c|c|c|c|c|}
\hline CFRP-M & $\begin{array}{c}\text { Load Z } \\
{[\mathbf{\%}]}\end{array}$ & $\begin{array}{c}\text { Df } \\
{[\mathbf{\%}]}\end{array}$ & $\begin{array}{c}\mathbf{R a} \\
{[\boldsymbol{\mu \mathbf { m } ]}}\end{array}$ & $\begin{array}{c}\mathbf{R z} \\
{[\boldsymbol{\mu m}]}\end{array}$ \\
\hline 1a & 20 & 2.5 & 0.89 & 5.47 \\
\hline 1b & 10 & 1.9 & 1.13 & 6.40 \\
\hline 2a & 20 & 10.6 & 0.81 & 6.17 \\
\hline 2b & 15 & 22.5 & 0.81 & 6.29 \\
\hline $3 \mathrm{a}$ & 20 & 31.8 & 1.64 & 10.30 \\
\hline $3 \mathrm{~b}$ & 10 & 22.8 & 1.57 & 10.75 \\
\hline $4 \mathrm{a}$ & 20 & 21.2 & 1.39 & 7.84 \\
\hline 4b & 10 & 17.8 & 1.39 & 8.48 \\
\hline avg. a & $\mathbf{2 0}$ & $\mathbf{1 6 . 5}$ & $\mathbf{1 . 1 9}$ & $\mathbf{7 . 4 5}$ \\
\hline avg. b & $\mathbf{1 1 . 2 5}$ & $\mathbf{1 6 . 2}$ & $\mathbf{1 . 2 3}$ & $\mathbf{7 . 9 8}$ \\
\hline
\end{tabular}

Table 3. Results of the measurements for CFRP type M

\section{Conclusion}

The obtained results allow us to conclude that ultrasonic assistance has a great influence on the reduction of machine tool load (decreasing by approx. $44 \%$ for GFRP and decrease by approx. $60 \%$ for CFRP-S and $44 \%$ for CFRP-M). The surface roughness parameters were not significantly affected. Width of the delamination was also very similar (elevation by approx. $16 \%$ for GFRP and reduction by approx. $11 \%$ for CFRP-S and 2\% for CFRP-M). Generally, during machining of GFRP was achieved lower machine load, lower delamination and higher surface roughness in comparison with machining of CFRP. During machining of CFRP-M (the one with lower tensile strength and higher modulus of elasticity) was achieved higher machine load, lower delamination and lower surface roughness in comparison with CFRP-S. Relatively low ultrasonic influence on delamination and surface roughness parameters could be caused by relatively low amplitude (tool was not directly manufactured for ultrasonic assistance - absence of concentrator). We also observed much lower delamination on the base surface of the GFRP rod and on the edge surface parallel to the fibres direction of the CFRP plate. On the lateral surface of GFRP was observed lower delamination at machining in direction of the fibres.

To sum up, ultrasonic assistance is proper especially in terms of decreasing of the machine tool load. Lower machine load allows usage of higher depth of cut and feed rate (increased material removal rate). It means, UAM allows increasing productivity even when common (cheap) cutting tool is used. If a tool will be designed for ultrasonic assistance, its improvement could be even greater. Results of unwanted delamination (edge-chipping of workpiece) could be applied in wanted cutting edge preparation (edge-chipping of tool). Further research will be focused on the determination of influence of ultrasonic assistance on different composite materials, such as metal matrix composite, or ceramic matrix composite, as well as sintered carbide for application as cutting tool with edge preparation.

\section{Acknowledgments}

This contribution is a part of the GA VEGA project of Ministry of Education, Science, Research and Sport of the Slovak Republic, No. 1/0477/14 "Research of influence of selected characteristics of machining process on achieved quality of machined surface and problem free assembly using high Technologies".

The article was written with the support of the Project of VEGA grant agency of the Ministry of Education, Science, Research and Sport of the Slovak Republic and Slovak Academy of Sciences, no. 1/0097/17: "The research of novel 
method for cutting edge preparation to increase the tool performance in machining of difficult-to-machine materials" and APVV Project of Slovak Research and development Agency of the Ministry of Education, Science, Research and Sport of the Slovak Republic, no. APVV-16-0057: "Research into the Unique Method for Treatment of Cutting Edge Microgeometry by Plasma Discharges in Electrolyte to Increase the Tool Life of Cutting Tools in Machining of Difficultto-Machine Materials."

\section{References}

[1] Dai Gil Lee, et al. (2017). Adhesion characteristics of fiber-exposed glass composites. In Composite Structures. Vol. 165, pp. 9-14.

[2] Aviation. Available on the Internet: https://aviation.stackexchange.com/questions/22148/are-composite-materialswhich-are-being-widely-used-in-newer-aircrafts-better

[3] Ning F., Wang H., Cong W., Fernando P.K.S.C. (2017). A mechanistic ultrasonic vibration amplitude model during rotary ultrasonic machining of CFRP. In Ultrasonics. Vol. 76, pp. 44-51.

[4] Su Z., Jia Z., Niu B., Bi G. (2017). Size effect of depth of cut on chip formation mechanism in machining of CFRP. In Composite Structures. Vol. 164, pp. 316-327.

[5] Khan M.A., Kumar A.S. (2011). Machinability of glass fibre reinforced plastic (GFRP) composite using aluminabased ceramic cutting tools. In Journal of Manufacturing Process. Vol. 13, Issue 1, pp. 67-73.

[6] Sonkar V., Abhishek K., Datta S., Mahapatra S.S. (2014). Multi-objective Optimization in Drilling of GFRP Composites: A Degree of Similarity Approach. In Procedia Materials Science. Vol. 6, pp. 538-543.

[7] Sreenivasaulu R. (2013). Optimization of Surface Roughness and Delamination Damage of GFRP Composite Material in End Milling using Taguchi Design Method and Artificial Neural Network. In Procedia Engineering. Vol. 64, pp. 785-794.

[8] Akbari J., et al. (2013). Applying Ultrasonic Vibration to Decrease Drilling-Induced Delamination in GFRP Laminates. In Procedia CIRP. Vol. 6, pp. 577-582.

[9] Palanikumar K. (2011). Experimental investigation and optimisation in drilling of GFRP composites. In Measurement. Vol. 44, Issue 10, pp. 2138-2148.

[10] Bosco M.A.J., Palanikumar K., Prasad B.D., Velayudham A. (2013). Influence of Machining Parameters on Delamination in Drilling of GFRP-armour Steel Sandwich Composites. In Procedia Engineering, pp. 758-763.

[11] Direct Industry - Product: Seco Tools. Available on the Internet: http://www.directindustry.com/prod/seco-tools5699.html

[12] Kuruc M., Vopát T., Peterka J. (2015). Surface Roughness of Poly-crystalline Cubic Boron Nitride after Rotary Ultrasonic Machining. In Procedia Engineering. Vol. 100, pp. 877-884.

[13] Kuruc M., Zvončan M., Peterka J. (2014). Investigation of ultrasonic assisted milling of aluminum alloy AlMg4.5Mn. In Procedia Engineering. Vol. 69, pp. 1048-1053.

[14] Kuruc M. (2015). Machine tool loads in rotary ultrasonic machining of alumina, CBN and synthetic diamond. In Proceedings of the 26th DAAAM International Symposium, pp. 519-523. ISSN 1726-9679. ISBN 978-3-90273407-5.

[15] Delcam - Advanced manufacturing solutions. PowerMILL. Available on the Internet: http://www.powermill.com/

[16] Zvončan M., Kováč M., Beňo M. (2012). Machine tool’s DMG Ultrasonic 20 linear simulation in Powermill CAM software. In: CA systems in production planning. ISSN 1335-3799. Vol. 12, No 1, p. 90-93.

[17] Siemens. Sinumerik 840D. Available on the Internet: http://w3.siemens.com/mcms/mc-systems/en/automationsystems/cnc-sinumerik/Pages/cnc-systems.aspx

[18] Hufschmied: CATALOGUE PLASTIC-MACHINING. Available on the Internet: http://www.hufschmied.net/tl_files/dokumente/HUF-Kuststoff-Low-080415.pdf

[19] SECO Tools. Monolithic Carbide Mills. Available on the Internet: https://www.secotools.com/CorpWeb/Czech\%20Republic/katalogy/2015/CZ_Catalog_Solid\%20end\%20mills_20 15_Inlay_LR.pdf

[20] Zeiss. Metrotom 1500. Available on the Internet: http://www.zeiss.com/industrialmetrology/en_de/products/systems/computedtomography/metrotom-1500.html

[21] Zeiss. SURFCOM 5000. Available on the Internet: http://www.zeiss.com/industrialmetrology/en_de/products/systems/form-andsurface/surface-and-contour/surfcom-5000.html 